\title{
The impact of HER2-directed targeted therapy on HER2-positive DCIS of the breast
}

\author{
Gary. D. Lewis ${ }^{1}$, Waqar Haque ${ }^{2}$, Andrew Farach ${ }^{2}$, Sandra S. Hatch ${ }^{3}$, E. Brian Butler ${ }^{2}$, Polly A. Niravath ${ }^{4}$, \\ Mary R. Schwartz, Elizabeth Bonefas ${ }^{6}$, Bin S. Teh ${ }^{2}$ \\ ${ }^{1}$ Department of Radiation Oncology, University of Arkansas for Medical Sciences, Little Rock, Arkansas, United States \\ ${ }^{2}$ Department of Radiation Oncology, Houston Methodist Hospital, Houston, Texas, United States \\ ${ }^{3}$ Department of Radiation Oncology, University of Texas Medical Branch, Galveston, Texas, United States \\ ${ }^{4}$ Department of Clinical Medicine in Oncology, Houston Methodist Hospital, Houston, Texas, United States \\ ${ }^{5}$ Department of Pathology and Genomic Medicine, Houston Methodist Hospital, Houston, Texas, United States \\ ${ }^{6}$ Breast Health Houston, Houston, Texas, United States
}

\begin{abstract}
Background: In invasive breast cancer, HER2 is a well-established negative prognostic factor. However, its significance on the prognosis of ductal carcinoma in situ (DCIS) of the breast is unclear. As a result, the impact of HER2-directed therapy on HER2-positive DCIS is unknown and is currently the subject of ongoing clinical trials.

In this study, we aim to determine the possible impact of HER2-directed targeted therapy on survival outcomes for HER2-positive DCIS patients.

Materials and methods: The National Cancer Data Base (NCDB) was used to retrieve patients with biopsy-proven DCIS diagnosed from 2004-2015. Patients were divided into two groups based on the adjuvant therapy they received: systemic HER2directed targeted therapy or no systemic therapy. Statistics included multivariable logistic regression to determine factors predictive of receiving systemic therapy, Kaplan-Meier analysis to evaluate overall survival (OS), and Cox proportional hazards modeling to determine variables associated with OS.

Results: Altogether, 1927 patients met inclusion criteria; 430 (22.3\%) received HER2-directed targeted therapy; 1497 (77.7\%) did not. Patients who received HER2-directed targeted therapy had a higher 5-year OS compared to patients that did not (97.7\% vs. $95.8 \%, p=0.043)$. This survival benefit remained on multivariable analysis. Factors associated with worse OS on multivariable analysis included Charlson-Deyo Comorbidity Score $\geq 2$ and no receipt of hormonal therapy.

Conclusion: In this large study evaluating HER2-positive DCIS patients, the receipt of HER2-directed targeted therapy was associated with an improvement in OS. The results of currently ongoing clinical trials are needed to confirm this finding.

Key words: DCIS; HER2; molecular status; targeted therapy; breast cancer

Rep Pract Oncol Radiother 2021;26(2):179-187
\end{abstract}

Address for correspondence: Dr. Bin S. Teh, Department of Radiation Oncology, Houston Methodist Hospital, Cancer Center, and Research Institute, Weil Cornell Medical College, 6565 Fannin, Ste\#DB1-077, Houston, Texas 77030, United States, tel: 713-441-4800, fax: 713-441-4493; e-mail: BTeh@houstonmethodist.org

This article is available in open access under Creative Common Attribution-Non-Commercial-No Derivatives 4.0 International (CC BY-NC-ND 4.0) license, allowing to download articles and share them with others as long as they credit the authors and the publisher, but without permission to change them in any way or use them commercially 


\section{Introduction}

Ductal carcinoma in situ (DCIS) of the breast is a pre-invasive form of breast cancer that is defined by neoplastic proliferation of epithelial cells that is confined to the mammary ductal system [1]. It is estimated that DCIS makes up approximately $20 \%$ of all new diagnoses of breast cancer and up to $40 \%$ of all cases detected via mammogram [2-4]. While DCIS is a pre-cancerous lesion, finding DCIS warrants treatment as it is believed to be a precursor to invasive breast cancers (IBC) [5]. As a result, considerable research efforts have been aimed at understanding the mechanisms of this progression.

Although DCIS has been thought to be single disease entity, there is evidence that DCIS, much like invasive breast cancer, encompasses a broad and heterogenous group of diseases that can be differentiated by varying degrees of biological aggressiveness [6]. For example, classifying DCIS similarly to IBC may be a way to determine prognoses based on disease biology $[7,8]$. However, individualizing treatment options and management based on this information is still controversial. While patients with IBC receive personalized systemic treatment based on their specific molecular subtype, patients with DCIS are treated fairly uniformly. Indeed, after initial local therapy (surgery with or without radiotherapy), the hormone receptor status is the only factor that may affect systemic treatment [9-11].

However, there is growing interest in using HER2-targeted therapy for HER2-amplified DCIS patients. While there is conflicting evidence on the effect of HER2 positivity on disease characteristics and patient outcomes [7, 8, 12-17], there remains strong interest in the role of HER2-targeted therapy. The National Surgical Adjuvant Breast and Bowel Project (NSABP) is currently running a clinical trial (B-43) examining the effect of trastuzumab on the risk of in-breast tumor recurrence for patients with HER2 positive DCIS [4]. Given the lack of evidence and defined management guidelines, we aimed to use the National Cancer Data Base (NCDB) to determine the effects of HER2-targeted therapy on survival outcomes.

\section{Materials and methods}

This study used the NCDB, which is a hospital-based cancer registry sponsored by the Ameri- can College of Surgeons (ACoS) and the American Cancer Society. It collects data from over 1500 hospitals with ACoS-accredited cancer programs, accounting for $70 \%$ of all newly-diagnosed cases in the United States [18-22]. The most recent data from the NCDB included data from 2004-2015. A case list of patients with biopsy-proven DCIS was retrieved from the NCDB. Diagnosis was based on the International Classification of Disease for Oncology, third edition (ICD-O-3) codes of 8201, 8230, 8500, 8501, 8503, 8507, and 8522. Patients with invasive breast cancer were specifically excluded. In order to be included in the study, patients were required to have a positive HER2 status. No specific cutoffs for HER2 positivity are mandated by the NCDB but each institution is accredited by the American College of Surgeons and pathology reports are required to follow the format, criteria, and guidelines of the College of American Pathologists [23].

Patient characteristics retrieved and recorded included age, race, Charlson-Deyo comorbidity score, type of insurance, income, facility type, margin status, receipt of hormonal therapy, estrogen receptor (ER) status, progesterone receptor (PR) status, and DCIS grade. Patients who received systemic therapy were coded as having received HER2-targeted therapy. Because patients with DCIS are not candidates for non-endocrine, cytotoxic systemic therapy, this assumption was felt to be reasonable. Patients were divided into two cohorts: those who received HER2-targeted therapy and those who did not.

All statistical tests were two-sided, with a threshold of $p<0.05$ for statistical significance, and were performed using STATA (version 14, StataCorp, College Station, TX). The $\chi^{2}$ test analyzed categorical proportions between groups. Univariable and multivariable logistic regression modeling was utilized to determine characteristics that were predictive of the receipt of HER2-targeted therapy. The Kaplan-Meier method was used for survival analysis, and comparisons between the two treatment paradigms were performed with the log-rank test for all patients. Overall survival (OS) was defined as the interval between the date of diagnosis and the date of death or last contact. Multivariable Cox proportional hazards modeling was additionally used to identify variables associated with OS in the entire cohort. 


\section{Results}

Altogether, 1927 patients met the inclusion criteria. The majority of patients in the cohort were over the age of 50, Caucasian, had a Charlson-Deyo Comorbidity Score of 0 and were treated at a non-academic facility. Overall, $430(22.3 \%)$ received HER2-directed targeted therapy, while 1497 (77.7\%) did not. Patient characteristics for the two groups are listed in Table 1. Patients with ER(-) disease were more likely to receive HER2-directed targeted therapy. There was no relation between

Table 1. Baseline characteristics of patients in each of the cohorts

\begin{tabular}{|c|c|c|c|}
\hline Characteristic & $\begin{array}{l}\text { HER2-targeted therapy } \\
\qquad(n=430)(\%)\end{array}$ & $\begin{array}{l}\text { No HER2-targeted therapy } \\
\qquad(n=1497)(\%)\end{array}$ & p-value \\
\hline Age (years) & & & 0.601 \\
\hline$\leq 50$ & $92(21.4 \%)$ & $303(20.2 \%)$ & \\
\hline$>50$ & $338(78.6 \%)$ & $1194(79.8 \%)$ & \\
\hline Race & & & 0.778 \\
\hline Caucasian & $371(86.3 \%)$ & $1271(84.9 \%)$ & \\
\hline African American & $41(9.5 \%)$ & $157(10.5 \%)$ & \\
\hline Other/ not recorded & $18(4.2 \%)$ & $69(4.6 \%)$ & \\
\hline Charlson-Deyo Score & & & 0.813 \\
\hline 0 & $374(87.0 \%)$ & $1319(88.1 \%)$ & \\
\hline 1 & $50(11.6 \%)$ & $18(10.6 \%)$ & \\
\hline$\geq 2$ & $6(1.4 \%)$ & $20(1.3 \%)$ & \\
\hline Insurance & & & 0.670 \\
\hline Medicaid & $25(5.8 \%)$ & $86(5.7 \%)$ & \\
\hline Private & $274(63.7 \%)$ & $902(60.3 \%)$ & \\
\hline Medicare & $116(27.0 \%)$ & $455(30.4 \%)$ & \\
\hline Uninsured & $8(1.9 \%)$ & $24(1.6 \%)$ & \\
\hline Government/other & $7(1.6 \%)$ & $30(2.0 \%$ & \\
\hline Income & & & 0.457 \\
\hline$\leq 62999$ USD & $281(65.4 \%)$ & $938(62.7 \%)$ & \\
\hline$\geq 63000$ USD & $147(34.2 \%)$ & $555(37.1 \%)$ & \\
\hline Not recorded & $2(0.5 \%)$ & $4(0.3 \%)$ & \\
\hline Facility type & & & 0.432 \\
\hline Academic & $108(25.1 \%)$ & $417(27.9 \%)$ & \\
\hline Non-academic & $317(73.7 \%)$ & $1068(71.3 \%)$ & \\
\hline Not recorded & $5(1.2 \%)$ & $12(0.8 \%)$ & \\
\hline Margin status & & & 0.306 \\
\hline Negative & $416(96.7 \%)$ & $1440(96.2 \%)$ & \\
\hline Positive & $10(2.3 \%)$ & $50(3.3 \%)$ & \\
\hline Not recorded & $4(0.9 \%)$ & $7(0.5 \%)$ & \\
\hline Hormonal therapy & & & 0.898 \\
\hline Yes & $220(51.2 \%)$ & 777 (51.9\%) & \\
\hline No & $167(38.8 \%)$ & $581(38.8 \%)$ & \\
\hline Not recorded & $43(10.0 \%)$ & $139(9.3 \%)$ & \\
\hline
\end{tabular}


Table 1. Baseline characteristics of patients in each of the cohorts

\begin{tabular}{|c|c|c|c|}
\hline Characteristic & $\begin{array}{l}\text { HER2-targeted therapy } \\
\qquad(n=430)(\%)\end{array}$ & $\begin{array}{l}\text { No HER2-targeted therapy } \\
\qquad(\mathrm{n}=1497)(\%)\end{array}$ & p-value \\
\hline \multicolumn{3}{|c|}{ Estrogen receptor status } & 0.034 \\
\hline Positive & 261 (60.7\%) & $992(66.3 \%)$ & \\
\hline Negative & $169(39.3 \%)$ & 499 (33.3\%) & \\
\hline Not recorded & $0(0.0 \%)$ & $6(0.4 \%)$ & \\
\hline \multicolumn{3}{|c|}{ Progesterone receptor status } & 0.665 \\
\hline Positive & 199 (46.3\%) & $726(48.5 \%)$ & \\
\hline Negative & $221(51.4 \%)$ & 742 (49.6\%) & \\
\hline Not recorded & $10(2.3 \%)$ & $29(1.9 \%)$ & \\
\hline \multicolumn{3}{|l|}{ Grade } & 0.295 \\
\hline 1 & $13(3.0 \%)$ & $57(3.8 \%)$ & \\
\hline 2 & 65 (15.1\%) & $278(18.6 \%)$ & \\
\hline 3 & $275(64.0 \%)$ & 897 (59.9\%) & \\
\hline Not recorded & 77 (17.9\%) & 265 (17.7\%) & \\
\hline
\end{tabular}

the receipt of HER2-directed targeted therapy and insurance type, income, facility type, margin status, grade, or receipt of hormonal therapy.

The Kaplan-Meier curves comparing survival for patients either receiving treatment with or without HER2- directed therapy are illustrated in Figure 1. Patients who received HER2-directed targeted therapy had a higher 5-year OS compared to pa- tients that did not $(97.7 \%$ vs. $95.8 \%, \mathrm{p}=0.043$, Fig. 1). This survival benefit for HER2-directed targeted therapy remained statistically significant on multivariable analysis. On multivariable analysis, factors associated with worse OS included Charlson-Deyo Comorbidity Score $\geq 2$ and no receipt of hormonal therapy. The results of the univariable and multivariable analysis are displayed in Table 2.

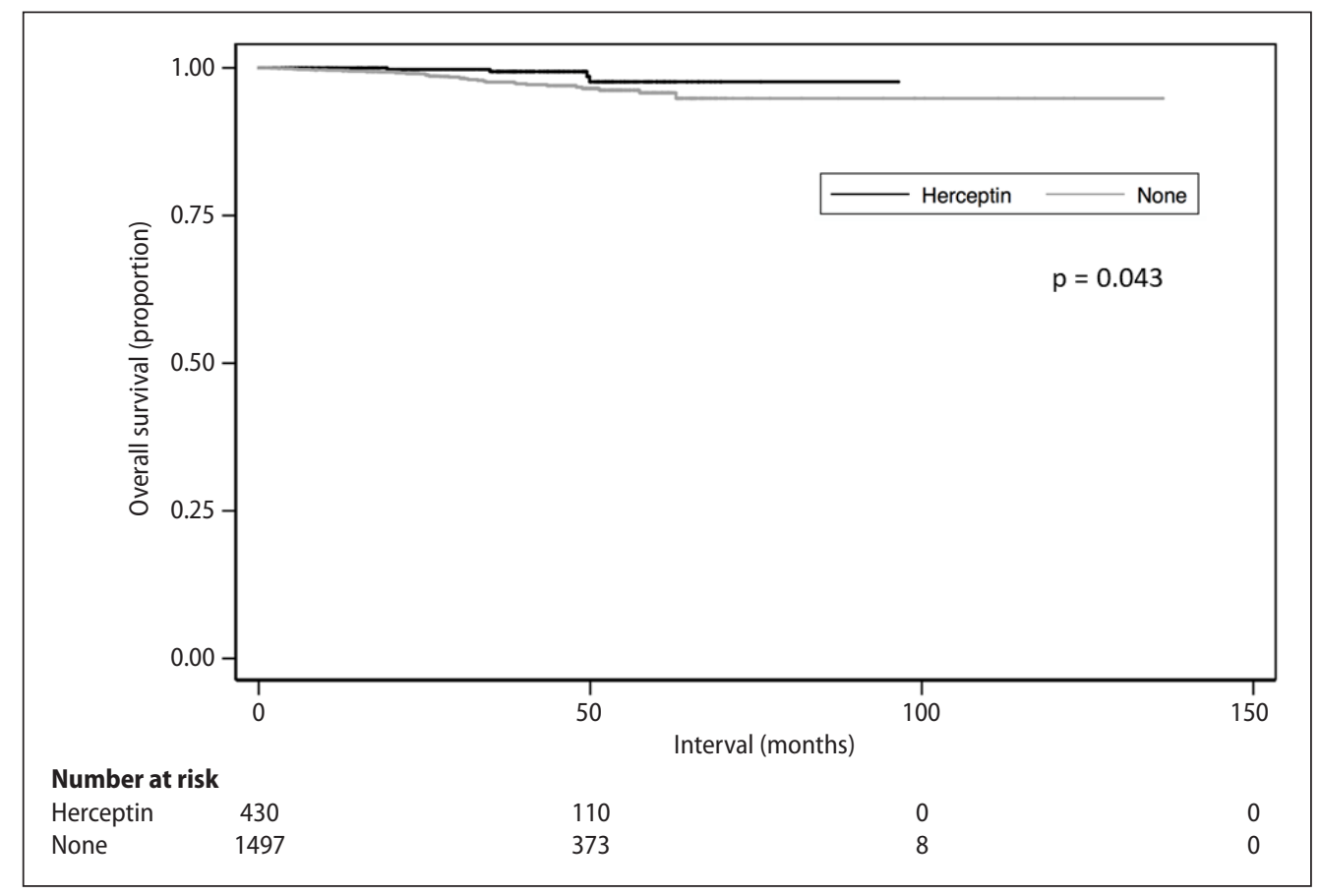

Figure 1. Overall survival stratified by receipt of HER2-directed targeted therapy 

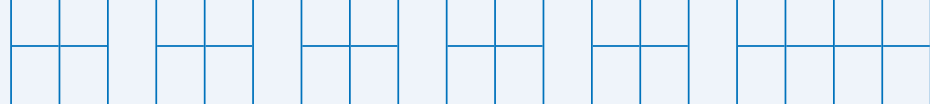

$\frac{t}{9}$

$\frac{\pi}{0}$

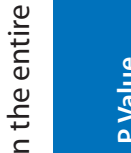

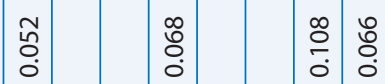

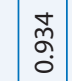

0

0
0 $\quad \tilde{o}$

웅

疍

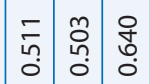

$\stackrel{\bar{m}}{\sum_{3}^{3}}$
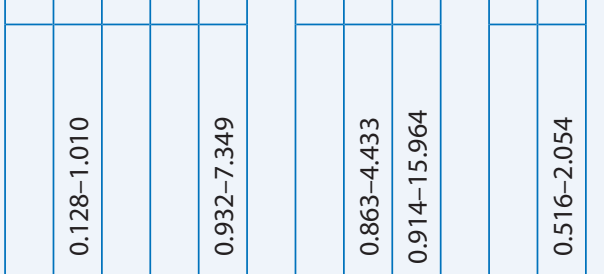

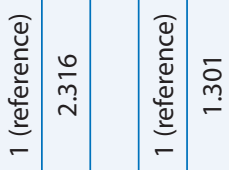

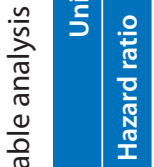

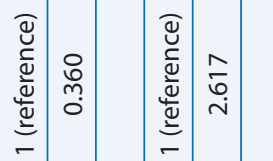

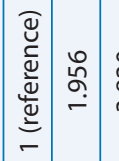

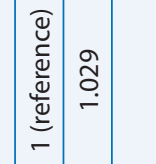

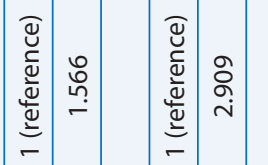

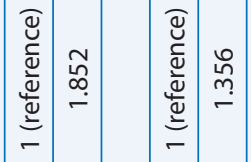

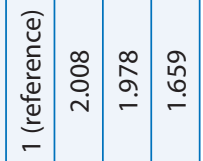
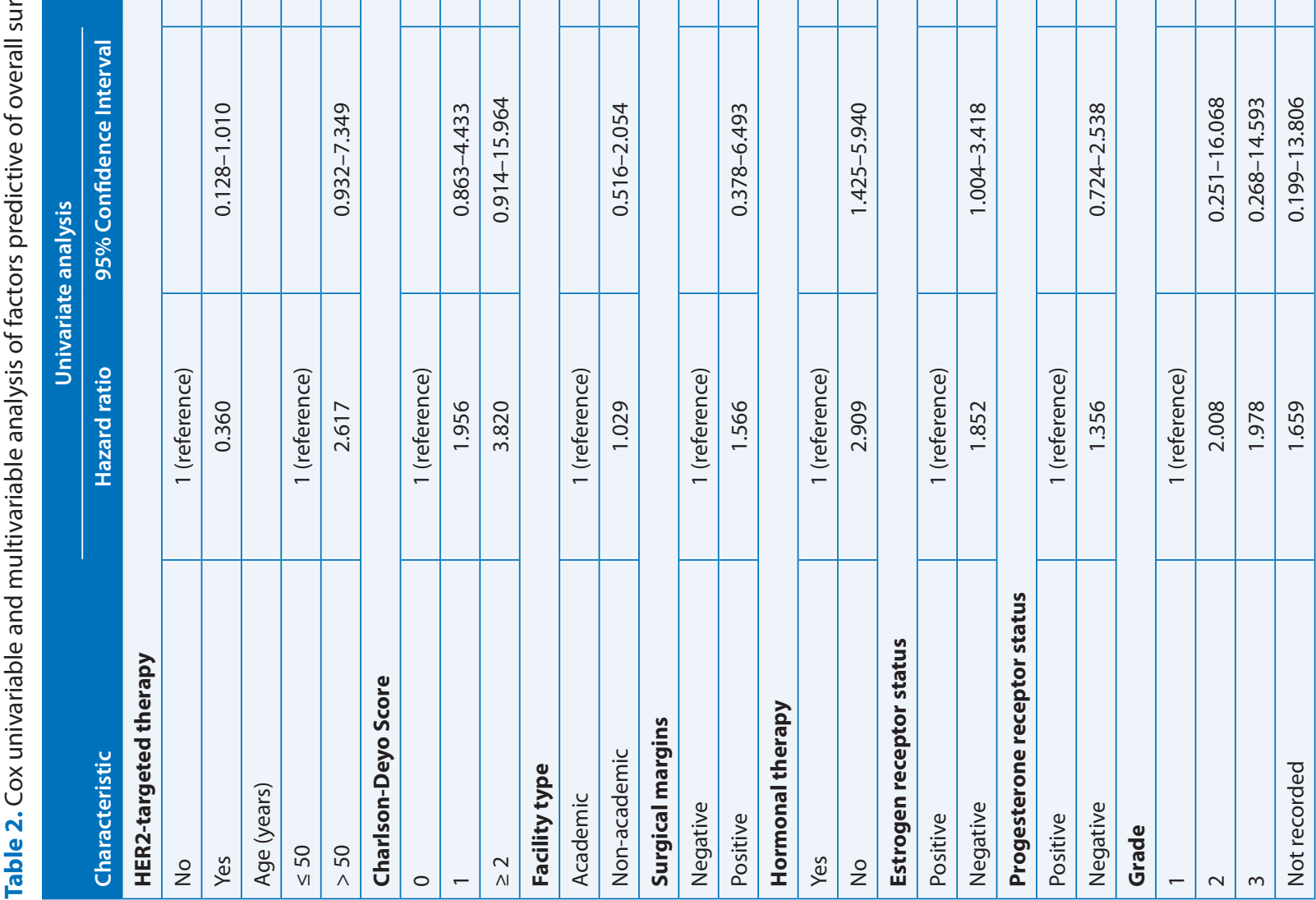

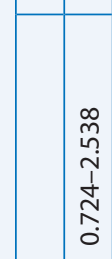

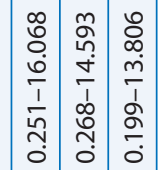




\section{Discussion}

To the best of our knowledge, this study represents the largest study of HER2 positive DCIS patients. In addition, this analysis is the first to examine the potential impact of HER2-directed targeted therapy on survival outcomes for DCIS patients. Several observations can be made from this analysis. First, as expected, the overall survival of all patients with HER2 positive DCIS was very high, with OS rates at five years $>95 \%$ with or without the use of HER2-targeted therapy. Second, the presumed use of HER2-targeted therapy was associated with improved OS amongst patients with HER2 positive DCIS. These results are interesting and highlight the importance of the NSABP B-43 clinical trial results, as the patient characteristics of our study population are similar to patients that were enrolled in the B-43 trial. A comparison of the patient characteristics collected from that trial with a comparison of our data is displayed in Table 3. The distribution of age and hormone receptor status between the two cohorts was similar. Our study population had slightly lower rates of high-grade DCIS compared to the B-43 cohort, which may have been due to higher rates of unrecorded tumor grade in the NCDB. Overall, HER2 positivity in our cohort was associated with high nuclear grade, which is concordant with the existing literature $[4,24-26]$.

This is the first study to suggest that the use of HER2-directed therapy is associated with an im- provement in overall survival amongst patients with HER2 positive DCIS. Our study is also the first to indicate a potential clinical benefit on survival outcomes for this patient population. Previous work has demonstrated that trastuzumab can effectively cross the basement membrane of the ductal system and may have clinical efficacy for HER2 positive DCIS [27-29]. If the NSABP trial has similar findings, HER2-directed targeted therapy may allow more treatment options for patients with DCIS, especially those with HR receptor negative disease. In addition, due to the significant heterogeneity of DCIS, another available targeted treatment option opens the door for more personalized cancer treatment. Finally, HER2-directed targeted therapy may serve as a mechanism to reduce the risk of progression of DCIS to invasive cancer, opening up the possibility of HER2-directed targeted therapy as a form of monotherapy.

Overall, HER2-directed therapy (in the form of trastuzumab) has demonstrated a strong safety record. In a preliminary report of HER2 positive DCIS patients in NSABP B- $43,5 \%$ of patients in the trastuzumab arm reported grade 3 toxicities with no cases of grade 4 or 5 toxicities [4]. In invasive breast cancer, trastuzumab has been studied extensively and found to have an acceptable safety pattern, even with regards to cardiotoxicity [30-32]. However, when compared to invasive cancer, the therapeutic ratio of trastuzumab for HER2 positive DCIS may not be as strong. DCIS patients as

Table 3. Comparison of HER2 positive DCIS patient characteristics between our study and the NSABP B-43 trial [4]

\begin{tabular}{|c|c|c|c|c|}
\hline \multirow[b]{2}{*}{ Characteristic } & \multicolumn{2}{|c|}{ Current Study } & \multicolumn{2}{|c|}{ NSABP B-43 trial [4] } \\
\hline & $\begin{array}{l}\text { HER2-targeted therapy } \\
\qquad(n=430)(\%)\end{array}$ & $\begin{array}{c}\text { No HER2-targeted } \\
\text { therapy } \\
(n=1497)(\%)\end{array}$ & $\begin{array}{l}\text { HER2-targeted therapy } \\
\qquad(n=713)(\%)\end{array}$ & $\begin{array}{c}\text { No HER2-targeted } \\
\text { therapy } \\
(n=715)(\%)\end{array}$ \\
\hline \multicolumn{5}{|l|}{ Age (years) } \\
\hline$\leq 50$ & $92(21.4 \%)$ & $303(20.2 \%)$ & $161(22.6 \%)$ & $164(22.9 \%)$ \\
\hline$>50$ & $338(78.6 \%)$ & $1194(79.8 \%)$ & $552(77.4 \%)$ & $551(77.1 \%)$ \\
\hline \multicolumn{5}{|l|}{ Estrogen receptor status } \\
\hline Positive & $261(60.7 \%)$ & $992(66.3 \%)$ & $423(59.3 \%)$ & 409 (57.2\%) \\
\hline Negative & $169(39.3 \%)$ & $499(33.3 \%)$ & $290(40.7 \%)$ & $304(42.5 \%)$ \\
\hline Not recorded & $0(0.0 \%)$ & $6(0.4 \%)$ & $0(0.0 \%)$ & $2(0.3 \%)$ \\
\hline \multicolumn{5}{|l|}{ Grade } \\
\hline Well differentiated & $13(3.0 \%)$ & $57(3.8 \%)$ & $10(1.4 \%)$ & $5(0.7 \%)$ \\
\hline Moderately differentiated & $65(15.1 \%)$ & $278(18.6 \%)$ & $108(15.1 \%)$ & $122(17.1 \%)$ \\
\hline Poorly differentiated & $275(64.0 \%)$ & $897(59.9 \%)$ & $595(83.5 \%)$ & $588(82.2)$ \\
\hline Not recorded & 77 (17.9\%) & 265 (17.7\%) & - & - \\
\hline
\end{tabular}


a whole do very well in terms of survival outcomes. Indeed, our study found an OS of $95.8 \%$ at five years. Even with a survival benefit at 5 years for HER2-directed therapy, it is possible that with long term follow-up the toxicity of therapy may erase any benefits. As a result, it is likely that not all HER2 positive DCIS patients will benefit from treatment, only patients at the highest risk. The results of the NSABP B-43 trial are likely to be very helpful in delineating which patients receive benefit.

The cost of therapy must also be taken into account. As a monoclonal antibody, the costs of manufacturing trastuzumab are already significant, even without including costs associated with administration, monitoring, and staffing [33]. For a patient population that already does well, cost-effectiveness studies will need to be performed to determine the societal value of more aggressive treatment, especially in the current health care climate of continuously rising (and often prohibitive) costs.

Our study has several limitations due to its reliance on the NCDB. First, our study had a relatively short follow-up due to the lack of widespread HER2 reporting in the NCDB until more recently. However, there was still a significant difference in survival based on receipt of HER2-directed therapy, although it is possible that the survival curves may plateau or cross with additional follow-up. Next, we must acknowledge the retrospective nature of the study with all its associated biases. HER2 status is not normally assessed and reported in DCIS; there may be potential bias in the patients who underwent HER2 testing. This may explain why the percentage of patients receiving systemic targeted therapy in our study (22.3\%) was higher than expected; currently, there is no standard clinical indication for non-endocrine systemic therapy. In addition, the NCDB does not record the use of specific targeted agents. We had to assume that patients recorded as receiving systemic therapy received HER2-directed targeted therapy. Although this assumption cannot be assured, it is highly unlikely that DCIS patients received non-endocrine cytotoxic chemotherapy; it is much more likely that these patients received HER2-directed therapy, especially given that these patients all had HER2 positive disease.

The lack of central review of pathology specimens is another limitation. However, our patient characteristics were similar to those found in the NSABP B-43 trial (which did have central pathol- ogy review), giving credence to our findings. We must also point out that the definitions for HER2 positivity have changed over time. In 2007 , the definition of HER 2 positivity was $>30 \%$ of tumor cells positive by immunohistochemistry (IHC) or a ratio of HER 2 to CEP17 of $>2.2$ by in-situ hybridization (ISH) [34]. In 2013, this definition was adjusted to $>10 \%$ of tumor cells positive by IHC, which was consistent with the entry criteria for trials examining the role of trastuzumab [34]. Alternatively, for ISH, a HER2/CEP17 ratio of $>2$ (depending on the number of signals per cell) was used as a cutoff for HER2 positivity [34]. Additional changes to the guidelines were made in 2018 [35]. Given, the generally lower thresholds for HER 2 positivity in these refinements, the number of DCIS patients defined as HER2 positive would be expected to increase. The impact this would have on the benefit of HER2-directed targeted therapy is unclear.

\section{Conclusions}

In the treatment of HER2-positive DCIS patients, the presumed receipt of HER2-directed targeted therapy was associated with an improvement in OS. This survival benefit remained statistically significant on multivariable analysis. This study is the largest study of HER2 positive DCIS patients to date, and our findings highlight the need for additional prospective data; we eagerly await the results of the currently ongoing clinical trials on this topic.

\section{Conflict of interest}

The authors declare that no conflicts of interest exist.

\section{Funding}

There are no financial disclosures for the authors.

\section{Disclaimers}

Presented in part as an abstract at the 2018 San Antonio Breast Cancer Symposium.

\section{Acknowledgements}

None.

\section{Declarations}

There was no funding for this study. The authors report no conflicts of interest. This study follows the principles of the Declaration of Helsinki. As 
all patient information in the NCDB database is de-identified, this study was exempt from institutional review board evaluation.

\section{References}

1. WHO Classification of Tumours Editorial Board. Breast Tumours: WHO Classification of Tumours, 5th edition. Lyon (France): International Agency for Research on Cancer; 2019.

2. Siziopikou KP. Ductal carcinoma in situ of the breast: current concepts and future directions. Arch Pathol Lab Med. 2013; 137(4): 462-466, doi: 10.5858/arpa.2012-0078-RA, indexed in Pubmed: 23544935.

3. Siegel R, Miller K, Jemal A. Cancer statistics, 2019. CA: A Cancer Journal for Clinicians. 2019; 69(1): 7-34, doi: 10.3322/caac.21551, indexed in Pubmed: 30620402.

4. Siziopikou KP, Anderson SJ, Cobleigh MA, et al. Preliminary results of centralized HER2 testing in ductal carcinoma in situ (DCIS): NSABP B-43. Breast Cancer Res Treat. 2013; 142(2): 415-421, doi: 10.1007/s10549-013-2755-z, indexed in Pubmed: 24202240.

5. Page D, Dupont W, Rogers L, et al. Intraductal carcinoma of the breast: Follow-up after biopsy only. Cancer. 1982; 49(4): 751-758, doi: 10.1002/1097-0142(19820215)49: $4<751::$ aid-cncr2820490426>3.0.co;2-y, indexed in Pubmed: 6275978.

6. Burstein HJ, Polyak K, Wong JS, et al. Ductal carcinoma in situ of the breast. N Engl J Med. 2004; 350(14): 1430-1441, doi: 10.1056/NEJMra031301, indexed in Pubmed: 15070793.

7. Williams KE, Barnes NLP, Cramer A, et al. Molecular phenotypes of DCIS predict overall and invasive recurrence. Ann Oncol. 2015; 26(5): 1019-1025, doi: 10.1093/annonc/ mdv062, indexed in Pubmed: 25678586.

8. Takahashi S, Thike AA, Koh VC, et al. Triple-negative and HER2 positive ductal carcinoma in situ of the breast: characteristics, behavior, and biomarker profile. Virchows Arch. 2018; 473(3): 275-283, doi: 10.1007/s00428-018-2416-z, indexed in Pubmed: 30033510.

9. Fisher B, Dignam J, Wolmark N, et al. Tamoxifen in treatment of intraductal breast cancer: National Surgical Adjuvant Breast and Bowel Project B-24 randomised controlled trial. Lancet. 1999; 353(9169): 1993-2000, doi: 10.1016/ S0140-6736(99)05036-9, indexed in Pubmed: 10376613.

10. Fisher B, Dignam J, Wolmark N, et al. Lumpectomy and radiation therapy for the treatment of intraductal breast cancer: findings from National Surgical Adjuvant Breast and Bowel Project B-17. J Clin Oncol. 1998; 16(2): 441-452, doi: 10.1200/JCO.1998.16.2.441, indexed in Pubmed: 9469327.

11. Allred DC, Anderson SJ, Paik S, et al. Adjuvant tamoxifen reduces subsequent breast cancer in women with estrogen receptor-positive ductal carcinoma in situ: a study based on NSABP protocol B-24. J Clin Oncol. 2012; 30(12): 1268-1273, doi: 10.1200/JCO.2010.34.0141, indexed in Pubmed: 22393101.

12. Borgquist S, Zhou W, Jirström K, et al. The prognostic role of HER2 expression in ductal breast carcinoma in situ (DCIS); a population-based cohort study. BMC Cancer. 2015; 15: 468, doi: 10.1186/s12885-015-1479-3, indexed in Pubmed: 26062614.
13. Davis JE, Nemesure B, Mehmood S, et al. Her2 and Ki67 Biomarkers Predict Recurrence of Ductal Carcinoma in Situ. Appl Immunohistochem Mol Morphol. 2016; 24(1): 20-25, doi: 10.1097/PAl.0000000000000223, indexed in Pubmed: 26317313.

14. Poulakaki N, Makris GM, Battista MJ, et al. Hormonal receptor status, Ki-67 and HER2 expression: Prognostic value in the recurrence of ductal carcinoma in situ of the breast? Breast. 2016; 25:57-61, doi: 10.1016/j.breast.2015.10.007, indexed in Pubmed: 26612082.

15. Daoud SA, Ismail WM, Abdelhamid MS, et al. Possible Prognostic Role of HER2/Neu in Ductal Carcinoma In Situ and Atypical Ductal Proliferative Lesions of the Breast. Asian Pac J Cancer Prev. 2016; 17(8): 3733-3736, indexed in Pubmed: 27644608.

16. Mustafa RE, DeStefano LM, Bahng J, et al. Evaluating the Risk of Upstaging HER2-Positive DCIS to Invasive Breast Cancer. Ann Surg Oncol. 2017; 24(10): 29993003, doi: 10.1245/s10434-017-5941-0, indexed in Pubmed: 28766212.

17. Di Cesare P, Pavesi L, Villani L, et al. The Relationships between HER2 Overexpression and DCIS Characteristics. Breast J. 2017; 23(3): 307-314, doi: 10.1111/tbj.12735, indexed in Pubmed: 27943525.

18. Lewis GD, Haque W, Butler EB, et al. Survival Outcomes and Patterns of Management for Anal Adenocarcinoma. Ann Surg Oncol. 2019; 26(5): 1351-1357, doi: 10.1245/ s10434-019-07202-4, indexed in Pubmed: 30719638.

19. Lewis GD, Haque W, Verma V, et al. The Role of Adjuvant Radiation Therapy in Locally Advanced Bladder Cancer. Bladder Cancer. 2018; 4(2): 205-213, doi: 10.3233/BLC180163, indexed in Pubmed: 29732391.

20. Lewis GD, Xing Y, Haque W, et al. Prognosis of lymphotropic invasive micropapillary breast carcinoma analyzed by using data from the National Cancer Database. Cancer Commun (Lond). 2019; 39(1):60, doi: 10.1186/s40880-0190406-4, indexed in Pubmed: 31639071.

21. Lewis GD, Dalwadi SM, Farach A, et al. The Role of Adjuvant Radiotherapy in the Treatment of Pleural Mesothelioma. Ann Surg Oncol. 2019; 26(6): 1879-1885, doi: 10.1245/ s10434-019-07235-9, indexed in Pubmed: 30798447.

22. Lewis GD, Xing Y, Haque W, et al. The impact of molecular status on survival outcomes for invasive micropapillary carcinoma of the breast. Breast J. 2019; 25(6): 1171-1176, doi: 10.1111/tbj.13432, indexed in Pubmed: 31321854.

23. Cancer program standards: Ensuring patient-centered care. 2016 ed. https://www.facs.org/ /media/files/quality $\% 20$ rograms/cancer/coc/2016\%20coc\%20standards\%20manual_interactive\%20pdf.ashx.

24. Cornfield DB, Palazzo JP, Schwartz GF, et al. The prognostic significance of multiple morphologic features and biologic markers in ductal carcinoma in situ of the breast: a study of a large cohort of patients treated with surgery alone. Cancer. 2004; 100(11): 2317-2327, doi: 10.1002/ cncr.20260, indexed in Pubmed: 15160334.

25. Collins LC, Schnitt SJ. HER2 protein overexpression in estrogen receptor-positive ductal carcinoma in situ of the breast: frequency and implications for tamoxifen therapy. Mod Pathol. 2005; 18(5): 615-620, doi: 10.1038/ modpathol.3800360, indexed in Pubmed: 15696127.

26. Claus EB, Chu P, Howe CL, et al. Pathobiologic findings in DCIS of the breast: morphologic features, angiogenesis, HER-2/neu and hormone receptors. Exp Mol Pathol. 2001; 
70(3): 303-316, doi: 10.1006/exmp.2001.2366, indexed in Pubmed: 11418009.

27. Kuerer HM, Buzdar AU, Mittendorf EA, et al. Biologic and immunologic effects of preoperative trastuzumab for ductal carcinoma in situ of the breast. Cancer. 2011; 117(1): 39-47, doi: 10.1002/cncr.25399, indexed in Pubmed: 20740500.

28. Parham DM, Pinder SE. The impact of human epidermal growth factor receptor 2 neoadjuvant monoclonal antibody (trastuzumab) therapy in ductal carcinoma in situ of the breast. Histopathology. 2017; 70(6): 1009-1011, doi: 10.1111/his.13145, indexed in Pubmed: 27943389.

29. Gunia SR, Patel MS, Mamounas EP. Pathologic Complete Response of HER-2 Neu-Positive Invasive Ductal Carcinoma and Ductal Carcinoma In Situ following Neoadjuvant Chemotherapy plus Trastuzumab: A Case Report and Review of Literature. Case Rep Surg. 2012; 2012: 454273, doi: $10.1155 / 2012 / 454273$, indexed in Pubmed: 22606601.

30. Cobleigh MA, Vogel CL, Tripathy D, et al. Multinational study of the efficacy and safety of humanized anti-HER2 monoclonal antibody in women who have HER2-overexpressing metastatic breast cancer that has progressed after chemotherapy for metastatic disease. J Clin Oncol. 1999; 17(9): 2639-2648, doi: 10.1200/JCO.1999.17.9.2639, indexed in Pubmed: 10561337.

31. Slamon D, Eiermann W, Robert N, et al. Breast Cancer International Research Group. Adjuvant trastuzumab in
HER2-positive breast cancer. N Engl J Med. 2011; 365(14): 1273-1283, doi: 10.1056/NEJMoa0910383, indexed in Pubmed: 21991949.

32. Piccart-Gebhart MJ, Procter M, Leyland-Jones $B$, et al. Herceptin Adjuvant (HERA) Trial Study Team. Trastuzumab after adjuvant chemotherapy in HER2-positive breast cancer. N Engl J Med. 2005; 353(16): 1659-1672, doi: 10.1056/ NEJMoa052306, indexed in Pubmed: 16236737.

33. Kurian AW, Thompson RN, Gaw AF, et al. A cost-effectiveness analysis of adjuvant trastuzumab regimens in early HER2/neu-positive breast cancer. J Clin Oncol. 2007; 25(6): 634-641, doi: 10.1200/JCO.2006.06.3081, indexed in Pubmed: 17308268.

34. Wolff AC, Hammond ME, Hicks DG, et al. American Society of Clinical Oncology, College of American Pathologists. Recommendations for human epidermal growth factor receptor 2 testing in breast cancer: American Society of Clinical Oncology/College of American Pathologists clinical practice guideline update. Arch Pathol Lab Med. 2014; 138(2): 241-256, doi: 10.5858/arpa.2013-0953-SA, indexed in Pubmed: 24099077.

35. Wolff AC, Hammond ME, Allison $\mathrm{KH}$, et al. Human Epidermal Growth Factor Receptor 2 Testing in Breast Cancer: American Society of Clinical Oncology/College of American Pathologists Clinical Practice Guideline Focused Update. Arch Pathol Lab Med. 2018; 142(11): 1364-1382, doi: 10.5858/arpa.2018-0902-SA, indexed in Pubmed: 29846104. 